\title{
Distance, Trade, and Income - The 1967 to 1975 Closing of the Suez Canal as a Natural Experiment*
}

\author{
James Feyrer $^{\dagger}$ \\ Dartmouth College and NBER
}

March 1, 2011

\begin{abstract}
The negative effect of distance on bilateral trade is one of the most robust findings in international trade. However, the underlying causes of this negative relationship are less well understood. This paper exploits a temporary shock to distance, the closing of the Suez canal in 1967 and its reopening in 1975, to examine the effect of distance on trade and the effect of trade on income. Time series variation in sea distance allows for the inclusion of pair effects which account for static differences in tastes and culture between countries. The distance effects estimated in this paper are therefore more clearly about transportation costs in the trade of goods than typical gravity model estimates. Distance is found to have a significant impact on trade with an elasticity that is about half as large as estimates from typical cross sectional estimates. Since the shock to trade is exogenous for most countries, predicted trade volume from the shock can be used to identify the effect of trade on income. Trade is found to have a significant impact on income. The time series dimension allows for country fixed effects which control for all long run income differences. Because identification is through changes in sea distance, the effect is coming entirely through trade in goods and not through alternative channels such as technology transfer, tourism, or foreign direct investment.
\end{abstract}

* Many thanks to Alan Taylor and Reuven Glick for sharing their bilateral trade data. Thanks to Jay Shambaugh, Doug Staiger, Liz Cascio, Doug Irwin, Nina Pavcnik and participants at the NBER Summer Institute for helpful comments. All errors are my own.

†james.feyrer@dartmouth.edu, Dartmouth College, Department of Economics, 6106 Rockefeller, Hanover, NH 03755-3514. fax:(603)646-2122. 


\section{Introduction}

The distance between countries has a substantial impact on the volume of trade between them 1 Why should distance matter? The most obvious answer is that trade is a function of transportation costs (which rise with distance). However, a calculation by Grossman (1998) suggests that transportation costs can only account for a fraction of the elasticity estimated by typical gravity regressions.

Gravity model estimates of the effect of distance on trade are likely to capture more than just transport costs. If tastes and cultural characteristics diverge with increasing distance, trade may decrease with distance even if transportation was costless 2 While some cultural aspects of bilateral relationships like common languages or colonial status can be controlled for, one can never completely eliminate missing variable bias in a cross section. For this reason, the distance coefficient in typical gravity regressions reflects many other aspects of distance beyond pure differences in transportation costs.

This paper estimates a gravity model of trade using novel variation that directly targets transportation costs - an exogenous time series shock to distance. On June 5, 1967, at the beginning of the Six Day War, Egypt closed the Suez canal. The canal remained closed for exactly eight years, reopening on June 5, 1975. The Suez Canal provides the shortest sea route between Asia and Europe and currently handles roughly 7.5 percent of world trade. The closure of the canal was a substantial unexpected shock to world trade. For most countries in the world, the closure of the Canal can be seen as an exogenous event. The reopening of the canal provides a similar shock in the opposite direction.

This paper will exploit these shocks to identify the effect of distance on trade and further to examine the effect of trade on output. Because there is time series variation, time and bilateral pair controls can be used to ensure that all identification comes from the change in distance due to the closure of the Suez Canal. By using variation caused by changes in sea distance, the estimates in this paper are much more closely focused on the pure impact of transportation costs compared to standard gravity estimates. The distance elasticities found in this paper are about half of those typically found in the literature. This suggests that less than half of

\footnotetext{
${ }^{1}$ A large literature has been produced testing gravity models of trade. Disdier and Head (2008) collect estimates of the impact of distance on trade from 108 papers.

${ }^{2}$ Blum and Goldfarb (2006) find that distance effects are substantial for goods consumed over the internet.
} 
the conventional estimates of distance on trade are working through transportation costs with the remainder reflecting other factors correlated with distance. The exogeneity of the shocks also makes it possible to estimate the time path of trade after the shock. Trade takes roughly three years to adjust to the shock.

The second part of the paper uses the exogenous variation in trade generated by the Suez shocks to identify the effect of trade on income. The effect of trade on income is of obvious interest and has been explored in numerous papers, but identification has been difficult due to reverse causality. 3 This paper approaches the identification problem in a manner similar to Frankel and Romer (1999), who use the distance between countries to predict bilateral trade volumes. The concern with their approach is that proximity may be acting through channels other than trade. 4 This paper is similar in the use of geography as an instrument for trade, but with the addition of time series variation provided by the Suez Canal shocks. This variation allows for the inclusion of country dummies in the second stage, controlling for all time invariant income differences.

This is similar to Feyrer (2009), where the identifying variation comes from the technological improvement in air transport. The income results in this paper differ in two important ways. First, Feyrer (2009) examines changes in trade that are slower moving and occur over decades. This paper exploits a short run shock to trade and is therefore more suited to thinking about events and policies that impact trade over the course of years, not decades. The short run nature of the shocks also allows for examining the time path of adjustment to the shocks.

The second important difference is that the variation in distance by sea generated by the closing of Suez is almost certainly identifying the effect of trade in goods. The approach of Feyrer (2009) may be picking up bilateral relationships fostered by inexpensive air travel such as foreign direct investment and trade in services that come from easier movement of people around the globe. These results can

\footnotetext{
${ }^{3}$ Sachs and Warner (1995), Frankel and Romer (1999), Dollar (1992), and Edwards (1998) are some of the more prominent papers finding a positive relationship between trade (or being open to trade) and income. Rodriguez and Rodrik (2000) conclude that none of these papers establish a robust and well identified relationship between trade restrictions and growth. The key difficulty faced in this literature is the lack of exogenous variation in trade or trade policies. Though some papers attempt to use instrumental variables, the instruments tend to violate exclusion restrictions.

${ }^{4}$ Rodriguez and Rodrik (2000) and others show that Frankel and Romer (1999)'s results are not robust to the inclusion of geographic controls in the second stage. For example, proximity to the equator is associated with low incomes. The Frankel and Romer (1999) instruments may be picking up this effect rather than trade. See also Rodrik, Subramanian and Trebbi (2004) and Irwin and Terviö (2002).
} 
therefore be seen as capturing the overall effect of globalization on income. Because the variation in this paper relies on sea distance, the effects must be coming through bilateral relationships that change when the distance by sea changes. Trade in goods is the main relationship that fits this description. This paper therefore can more clearly identify the relationship between trade in goods and output separately from other relationships that tend to move with trade.

The trade movements caused by the closing of the Suez Canal significantly change income with an elasticity of roughly one quarter. This is about half the value found in Feyrer (2009). This suggests that about half of positive impact of globalization is the result of trade in goods and half is due to other aspects of increased integration such as FDI or technology transfers caused by movements of people between countries.

Because of the unique identification in this paper, the results are more directly related to trade in goods than other gravity estimates. These results are therefore particularly useful for thinking about policies designed to decrease trade costs.

\section{The Six Day War and the Closure of the Suez Canal}

The Six Day War was fought between Israel and Egypt, Syria, and Jordan between June 5 and June 10 in 1967. In March of 1967 Egypt expelled the United Nations Emergency Force (UNEF). This force had been stationed on the Egypt-Israel border enforcing the armistice agreement that ended the Suez Crisis of 1956. The war began on June 5, as Israel launched surprise air strikes which destroyed the majority of the Egyptian Air Forces on the ground. At the end of the war Israel had greatly enlarged the territories under its control. The additions included the Sinai Peninsula and the Gaza strip from Egypt, the West Bank and East Jerusalem from Jordan, and the Golan Heights from Syria.

The canal was closed by Egypt at the outbreak of hostilities. Though tensions had been high in the region since the Suez Crisis of 1956, the actual outbreak of war was a surprise and the closing of the canal was not anticipated in advance. When the canal closed, fifteen cargo ships known as "The Yellow Fleet" were trapped inside. They remained in the canal during the entire eight years of the closure. Since it takes less than a day to transit the canal, this suggests that there was very little 
anticipation of the closing beforehand. At the end of the war, the canal was the cease fire line, with Israeli troops on one side and Egyptian troops on the other. These troops remained for the next eight years and there was little prospect of the canal reopening during most of this period. 5

In October of 1973, the Yom Kippur War was fought between Israel, Syria, and Egypt (Jordan did not take part). Egyptian forces crossed the Suez and attacked Israeli positions in the Sinai Peninsula. Syria staged a simultaneous offensive in the Golan Heights. After taking losses during the first few days, the Israelis counter attacked, retaking the Golan Heights on the northern front and splitting the Egyptian forces in the Sinai, pushing across the Canal. At the time of the UN brokered cease fire Israeli forces were on the west side of the canal and Egyptian forces were on the east side of the Canal.

The peace negotiations that followed involved reopening the canal. Agreement to reopen the canal was tentatively reached in early 1974. By March 5, 1974, the last of the Israeli troops had withdrawn from the west side of the canal. After fixing war damage and removing mines and munitions the canal reopened on June 5, 1975, eight years to the day of the closure. Unlike the closing, there was roughly a year of advance notice that the canal was to reopen.

The closure of the Canal provides a perfect natural experiment for examining the impact of distance on trade. For most pairs of countries the shock was unanticipated, sudden, and unimportant except through the effect on shipping costs. The nature of the shocks also makes it possible to identify the effect of trade on income.

\section{The Gravity Model}

The gravity model has been widely used for almost half a century. The basic idea that trade decreases with the distance between two countries is intuitive and holds up well empirically. This application of the gravity model is particularly straightforward since the nature of the shock is directly to distance. This allows for identifying the effect of distance in a panel of bilateral trade. The inclusion of bilateral pair dummies means that all identification comes from the change in distance caused by the closing

\footnotetext{
${ }^{5}$ The bleak prospects for reopening the canal during this period were confirmed by economist Joseph Zeira, who served as an Israeli army officer stationed along the canal during this time. Small skirmishes between the Israelis and Egyptians were common.
} 
of the Suez canal 6

Anderson and van Wincoop (2003) develop a theoretical model to derive the gravity model. The basic gravity relationship is

$$
\operatorname{trade}_{i j t}=\frac{y_{i t} y_{j t}}{y_{w t}}\left(\frac{\tau_{i j t}}{P_{i} P_{j}}\right)^{1-\sigma}
$$

where trade $_{i j t}$ is bilateral trade between country $i$ and country $j, y_{i t} y_{j t}$ and $y_{w t}$ are the incomes of country $i$, country $j$ and the world, $\tau_{i j t}$ is a bilateral resistance term, and $P_{i}$ and $P_{j}$ are country specific multilateral resistance terms. Taking logs,

$$
\ln \left(x_{i j}\right)=\ln \left(y_{i}\right)+\ln \left(y_{j}\right)-\ln \left(y_{w}\right)+(1-\sigma)\left(\ln \left(\tau_{i j t}\right)+\ln \left(P_{i}\right)+\ln \left(P_{j}\right)\right)
$$

The bilateral resistance term, $\tau_{i j t}$, in Equation (2) encompasses all pair specific barriers to trade such as distance, common language, a shared border, colonial ties, etc. The effect of distance is assumed to be log-linear. The majority of these determinants of bilateral resistance are time invariant and will be controlled for using bilateral pair dummies. The exception is, of course, the change in distance by sea caused by the closing and opening of the Suez Canal. The $P$ and $y$ terms will also be controlled for using bilateral pair dummies 7 The estimation equation is therefore

$$
\ln \left(\operatorname{trade}_{i j t}\right)=\alpha+\gamma_{i j}+\gamma_{t}+\beta \ln \left(\text { seadist }_{i j}\right)+\epsilon .
$$

The pair dummies (made possible through the time variation in distance) control perfectly for all long run determinants of bilateral trade such as common colonial heritage, shared tastes, etc.

\footnotetext{
${ }^{6}$ The distance measures that are commonly used in estimating gravity models are point to point great circle distances. Feyrer (2009) is the first to use sea distance in estimating a gravity model using comprehensive world trade data. While sea distance occasionally appears in gravity models, it has tended to be in the context of single country or regional studies. Disdier and Head (2008) conduct a meta study of gravity model results and cite the use of sea distance as one differentiator between papers. However the use of sea distance is rare and seems to be limited to regional work. Coulibalya and Fontagne (2005) consider sea distance in an examination of African trade.

${ }^{7}$ The individual income terms are time varying and will not be perfectly controlled for using the pair dummies. However, since the shock is exogenous to any particular countries income (except perhaps for the combatants and their neighbors, who are excluded) this should not bias the results. While it is possible to include a full set of country by year fixed effects, this would make the estimations invalid for constructing instruments for income.
} 


\subsection{Data}

Trade data were provided by Glick and Taylor (2008) who in turn are using the IMF Direction of Trade (DOT) data. For each bilateral pair in the DOT data there are potentially four observations in each year - imports and exports are reported from both sides of the pair. An average of these four values is used, except in the case where none of the four is reported. These values are taken as missing.

Bilateral sea distances were created by the author using raw geographic data. The globe was first split into a matrix of $1 x 1$ degree squares. The points representing points on land were identified using gridded geographic data from CIESIN 8 The time needed to travel from any oceanic point on the grid to each of its neighbors was calculated assuming a ship speed of 20 knots and adding (or subtracting) the speed of the average ocean current along the path. Average ocean current data are from the National Center for Atmospheric Research.9 The result of these calculations is a complete grid of the water of the globe with information on travel time between any two adjacent points. The grid can be constructed both including and excluding the Suez canal as a valid path. Given any two points in a network of points, the shortest travel time can be found using standard graph theory algorithms 10 After identifying a primary port for each country all pairwise minimum travel times were calculated from networks with and without the Suez canal as a valid path. For country pairs where the Suez canal is not the shortest path, these two travel times are identical. For country pairs including the Suez canal in the shortest path, the shortest alternative path is calculated. The distance between countries used in the regression is the number of days to make a round trip.

Identifying the location for the primary port for the vast majority of countries was straightforward and for most countries choosing any point along the coast would not change the results. The major potential exceptions to this are the US and Canada, with significant populations on both coasts and massive differences in distance depending on which coast is chosen. For simplicity (and because the east-west distribution of economic activity in the US and Canada can be seen as an outcome) the trade of the US and Canada with all partners was split with 80 percent attributed to the east coast and 20 to the west coast for all years. This

\footnotetext{
${ }^{8}$ http://sedac.ciesin.columbia.edu/povmap/ds_global.jsp

${ }^{9}$ Meehl (1980), http://dss.ucar.edu/datasets/ds280.0/

${ }^{10}$ Specifically, Djikstra's algorithm as implemented in the Perl module Boost-Graph-1.4 http://search.cpan.org/ dburdick/Boost-Graph-1.2/Graph.pm.
} 
is roughly based on the US east-west population distribution for 1970, the middle of the sample. In effect, the US and Canada are each split in two with regards to the trade regressions, with each country in the world trading with each coast independently based on appropriate sea distances. When generating predicted trade shares for the US and Canada, the trade with both halves are summed. Choosing just the east coast sea distances, changing the relative east-west weights, or even removing all observations including the US and Canada has no significant effect on the results.

Because countries need to abut the sea in order to be located on the oceanic grid, the sample excludes landlocked countries. Oil exporters were also left out of the sample because they have atypical trade patterns and have an almost mechanical relationship between the value of trade and income. Because of their involvement in the conflict all combatants and their immediate neighbors are excluded from the regressions. This eliminates Egypt, Israel, Jordan, Syria, Sudan, Libya, Lebanon, and Turkey. For most of these countries, their exclusion is not important for the results since they have ports on the Mediterranean side of the canal and most of their trade was unaffected by the closure. This is not true for Jordan and Sudan. In both cases, the shock to trade from the Suez closure was two to three times as big as for the next most affected nation in the data. Including Jordan would unambiguously strengthen the results for both trade and income. Including Sudan strengthens the trade results, but weakens the income results. In either case, their shocks are large enough that they have an exaggerated impact on the results when included.

The trade panel is unbalanced and only pairs that have at least one data point in the periods before, during, and after the closing of the canal are included in the analysis. There is some ambiguity as to whether missing values in the data are truly missing or represent zero trade. In order to check that this is not driving the results, balanced panel regressions will also be reported. Using a balanced panel of country pairs reduces the sample size by nearly one half (from 2,605 pairs to 1,294 pairs). Using just the balanced panel does not change the results significantly and leads to more precise estimates.

Data for income are GDP per capita measured in constant 2000 US\$ taken from the World Development Indicators. Johnson, Larson, Papageorgiou and Subramanian (2009) find that the Penn World Tables are inconsistent for high frequency 
applications and recommend the use of the World Development Indicators 11

For all the results that follow the sample will be comprised of trade for the years 1958 through 1984. The closure occurred over 9 calendar years so this provides for 9 full years before the closing and 9 full years after the reopening. For the income results, the initial period starts in 1960 because income data from the World Development Indicators are unavailable before 1960.

To present the results graphically, I will collapse the data into three periods, 1) 1960-1966 (before the closure), 2) 1970-1974 (during the closure), and 3) 1978-1984 (after the reopening). The shock year and two subsequent years are excluded from the analysis. As will be shown in the trade results, it takes trade about 3 years to fully adjust to the shock, so these windows are designed to capture the variables of interest after adjustment has taken place. The formal regressions will include results with and without including these transition periods.

\section{Did the Closure of the Suez Canal Reduce Trade?}

Figure 1 shows the average of residuals of log bilateral trade grouped by the size of the distance shock caused by the closure of Suez. The residuals are from a regression of the natural log of bilateral trade against a full set of time and bilateral pair dummies. For these graphs the sample is limited to country pairs with continuous data from 1958 to 1984. The vertical lines represent the closing and opening of the Suez Canal. There is a clear drop in trade during the closure for the groups with distance shocks of 10 percent or larger. The fall is larger for the groups with more extreme shocks. The modal country pair experiences no change in distance from the closing of the Canal. The shape of these graphs suggests that the impact of the closure on trade takes several years to reach its peak. In later sections, this time dynamic will be explored more formally.

Figure 2 is a scatter plot analogous to the gravity model estimation described in the previous section. On the $\mathrm{x}$-axis is the log change in distance by sea when Suez is closed and reopened. Points to the right of the origin represent the closing of the canal (distance increases) and to the left the reopening (distance decreases). Country pairs whose shortest sea routes do not use the Suez Canal (and therefore

\footnotetext{
${ }^{11}$ An earlier version of the paper used the PPP adjusted GDP per capita from the Penn World Tables 6.1. The results were similar to those presented here.
} 
Figure 1: Average bilateral trade residuals grouped by Suez Distance Increase

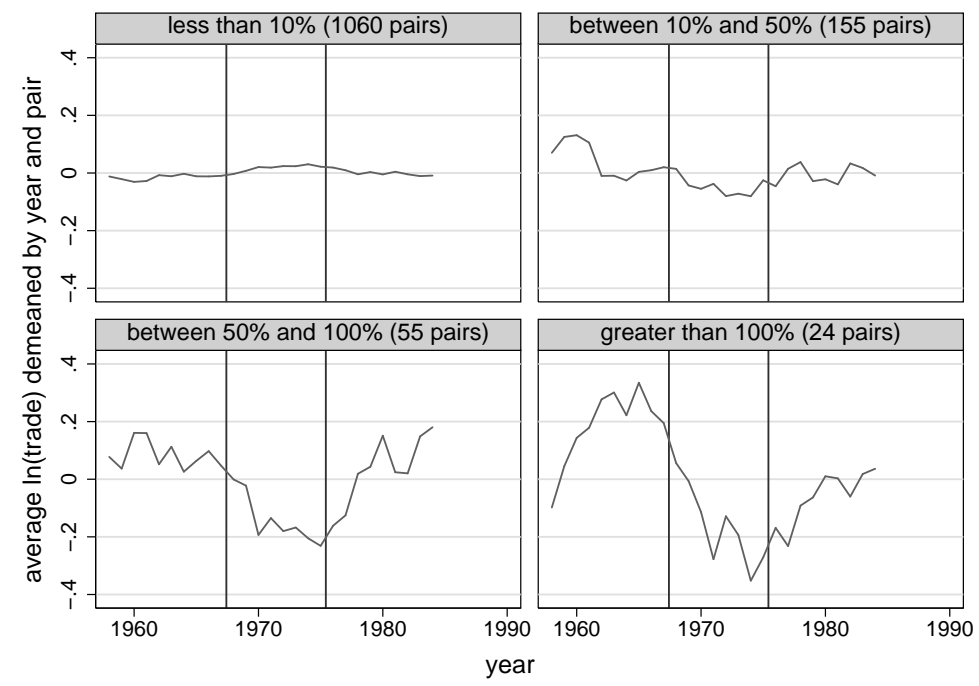

Source: IMF direction of trade database, author's calculations.

The vertical lines mark the closing and reopening of the Canal in 1967 and 1975.

Residuals from a regression with country pair and year dummies.

experience no shock) are omitted from this graph for clarity. About 23 percent of bilateral pairs representing 10 percent of the trade in the sample have the Suez canal as the shortest sea route. The y-axis is the change in log trade over two intervals. First, the change in average trade for years before the closure to years during the closure. Second, the change in average trade for years during the closure to years after the reopening. These averages are taken excluding the years of the opening and closing and the two years after these events. As will be shown later, omitting these years from the averages removes the transition period and better captures the long run effect.

Larger shocks to distance are associated with slower trade growth after the closure and more rapid trade growth after the reopening. An OLS regression matching the scatter generates a slope of -0.3 and it is significant at the one percent level. The distribution of shocks is skewed, with a small set of countries in the Indian Ocean and the Arabian Sea having the largest shocks. All pairs with a log distance increase of over one include one of the following countries on the Arabian Sea side of the canal: Djibouti, Pakistan, India, Kenya, Somalia, Tanzania and Sri Lanka. These are also the countries that experience the largest aggregate shocks, though Djibouti, Somalia, and Tanzania do not appear in the income regressions due to 
Figure 2: Log change in bilateral trade versus Suez Distance Change

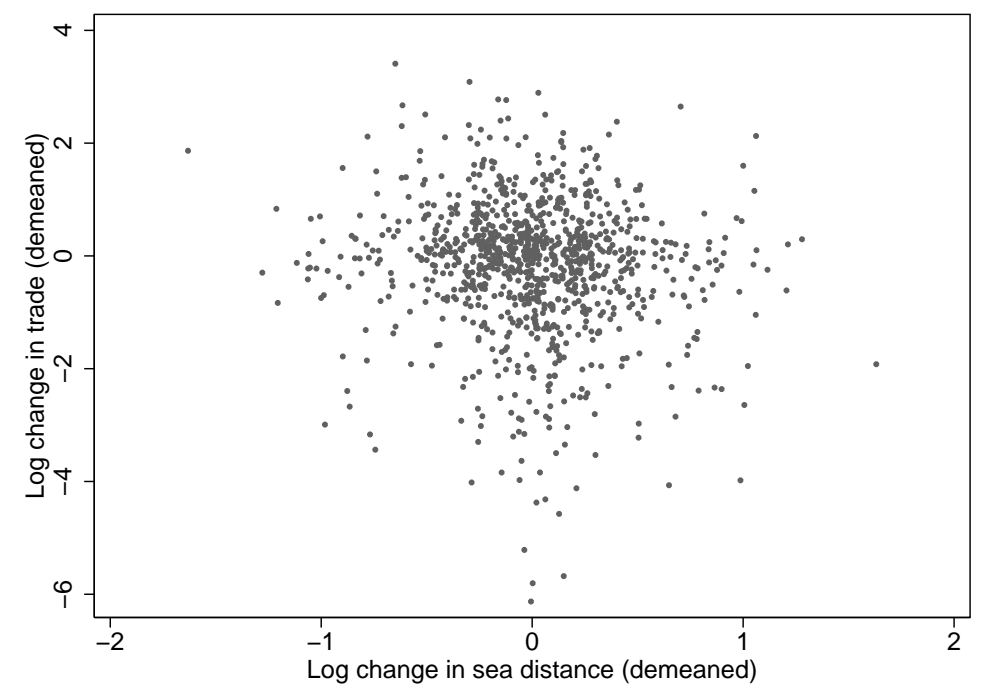

Source: IMF direction of trade database, author's calculations.

Trade change based on average for three periods, 1960-1966, 1970-1974, 1978-1984.

Points to the right of zero represent the change from before the closure to during the closure.

Points to the left of zero represent the change from during the closure to after reopening.

lack of data. Excluding all pairs with a log distance change of over one does not significantly change the estimates, so these large shocks are not driving the results.

Table 1 shows the results of running panel regression of log trade against sea distance (estimating equation 31). All the regressions include a full set of bilateral pair and year dummies. The bilateral dummies control for the time invariant factors that are typically included in gravity regressions such as common borders, colonial relationships, etc. All identification of the effect of distance on trade is coming from the change in sea distance caused by the closing (and reopening) of the Suez canal. Table 1 also includes regressions where the opening of Suez and the closing of Suez are treated as different shocks. It may be possible that the two shocks had different effects.

The results presented in Table 1 show that the average elasticity of trade with respect to sea distance is between 0.15 and 0.46 when the shocks are assumed to be symmetric. The even numbered columns exclude the transition years from the analysis and should better reflect the long run effect of the shock. Estimates that exclude the transition period are uniformly larger in absolute value. Moving to a balanced panel also tends to increase the absolute value of the point estimates.

Breaking the shock into two separate shocks suggests that the opening and the 
Table 1: Trade Versus Sea Distance with the Closure of Suez 67-75

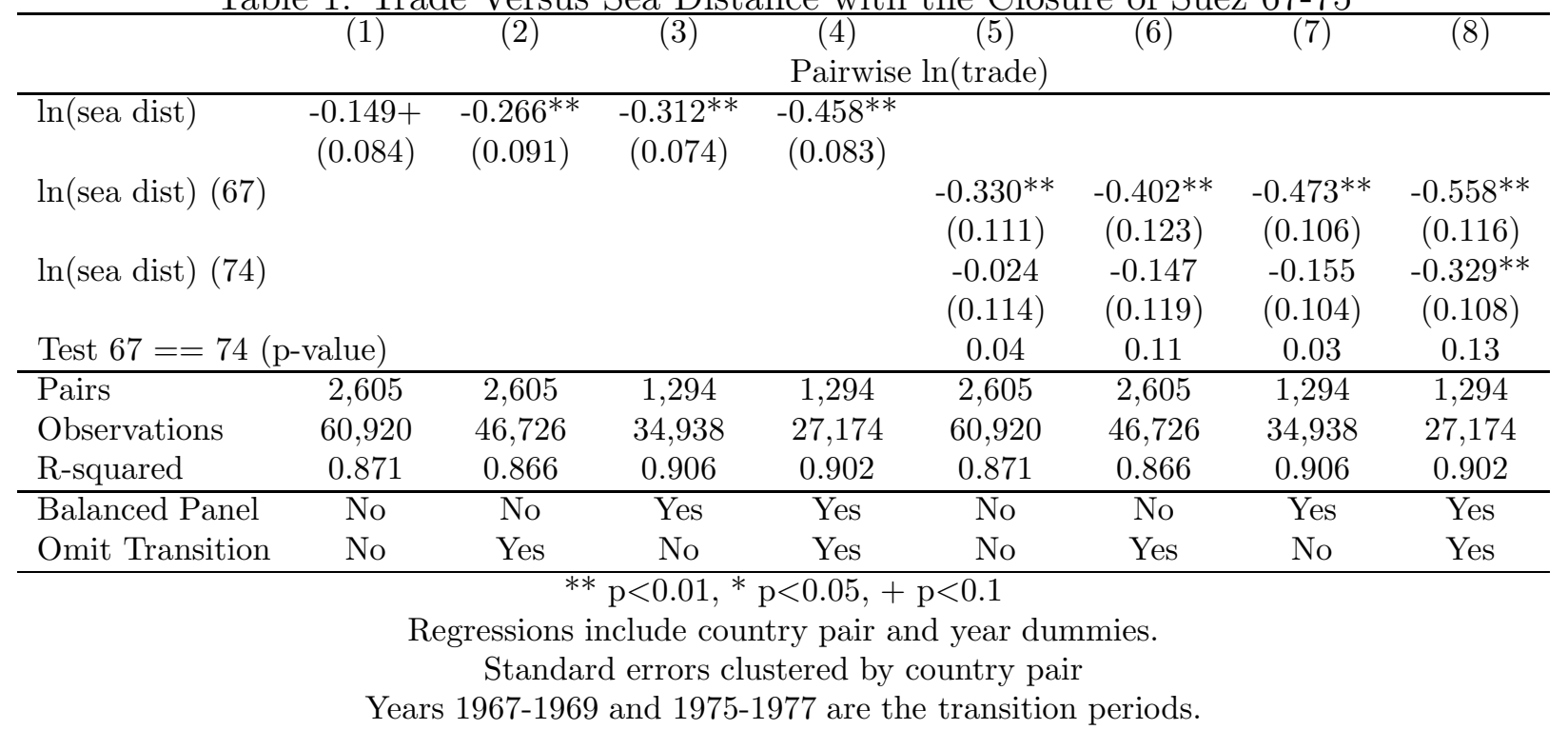

closing of the canal were not completely symmetric events. The elasticity of trade with respect to the shock is larger when estimated on the closure compared to the reopening, though the difference is only significant in estimations including the transition years. There are several reasons why they may be different. The reopening of the canal was anticipated for over a year, possibly muting the response, particularly during the transition. The closure was a complete surprise, leaving shippers scrambling to adjust shipping schedules. By the reopening, world trade had readjusted to a world without the canal. It is not unreasonable to think that shipping is more elastic to negative shocks than to positive ones given capacity that is fixed in the short run. A final reason for the smaller response is that the elasticity of trade with respect to sea distance may have fallen during this period in response to a growing volume of trade being carried by air 12

An estimated elasticity of trade with respect to distance of $0.2-0.5$ is smaller compared to standard gravity model estimates. In an extensive meta study of 103 gravity model studies Disdier and Head (2008) find an average elasticity of about 0.9 .

For comparison, Table 2 shows the results of more conventional gravity model estimation on the same data set used for Table 1, The distances used in this table do not change over time and the sea distance is the distance with the Suez Canal

\footnotetext{
${ }^{12}$ see Feyrer (2009)
} 
Table 2: Trade Versus Distance 1967-1975

\begin{tabular}{|c|c|c|c|c|c|c|}
\hline & $(1)$ & $(2)$ & $(3)$ & $(4)$ & $(5)$ & (6) \\
\hline & \multicolumn{6}{|c|}{ Pairwise $\ln$ (trade) } \\
\hline $\ln ($ air distance) & $\begin{array}{c}-1.084^{* *} \\
(0.031)\end{array}$ & & $\begin{array}{c}-0.791^{* *} \\
(0.072)\end{array}$ & $\begin{array}{c}-1.006^{* *} \\
(0.033)\end{array}$ & & $\begin{array}{c}-0.740^{* *} \\
(0.079)\end{array}$ \\
\hline $\ln ($ sea distance) & & $\begin{array}{c}-1.022^{* *} \\
(0.032)\end{array}$ & $\begin{array}{c}-0.309^{* *} \\
(0.072)\end{array}$ & & $\begin{array}{c}-0.922^{* *} \\
(0.035)\end{array}$ & $\begin{array}{c}-0.280^{* *} \\
(0.078)\end{array}$ \\
\hline Pairs & 2,605 & 2,605 & 2,605 & 1,294 & 1,294 & 1,294 \\
\hline Observations & 60,920 & 60,920 & 60,920 & 34,938 & 34,938 & 34,938 \\
\hline R-squared & 0.720 & 0.714 & 0.721 & 0.775 & 0.767 & 0.777 \\
\hline Balanced Panel & $\mathrm{No}$ & $\mathrm{No}$ & $\mathrm{No}$ & Yes & Yes & Yes \\
\hline
\end{tabular}

available. Because there is no time series variation in distance the regressions in this table include individual country dummies, not country pair dummies. The identification is entirely from the cross section as in conventional gravity estimates. The distance measure labeled "air distance" in these regressions is the point to point distance typically used in gravity estimations 13 The results are near the center of the results collected in Disdier and Head (2008). The lower coefficients found in Table 1 are therefore being driven by the use of time series variation and not anything inherent in the data set.

There are reasons to think that the traditional estimates are overstated. Typical gravity model regressions are run in a cross section with controls for characteristics of the pair such as a shared border, a shared language, or a colonial relationship. Obviously no set of controls can account for all the potential causes of bilateral resistance to trade and the coefficient on distance in such a regression may suffer from missing variable bias if distance is correlated with the missing variables.

\subsection{Impulse Response Functions}

Figure 1 suggests that trade took about 3 years to reach its low point after the closing and a similar amount of time to reach a new high after the reopening. Since the regressions from Table 1 are essentially comparing means of log trade from the three

\footnotetext{
${ }^{13}$ Specifically, I use the population weighted great circle distances between countries from the CEPII, http://www.cepii.fr/anglaisgraph/bdd/distances.htm. See Mayer and Zignago (2006) for a more complete description. Head and Mayer (2002) develop the methodology for the weighted measures.
} 
different periods, the full effect will only be reflected in the coefficient estimates if there is no adjustment path. The estimates from regressions omitting the transition years tend to be larger, implying that this is an important problem.

The time series nature of the data allows for looking at the time path of trade after the shock. Because the shock is exogenous, the estimation of the time path can be accomplished by including a series of lags of the shock in the regression. The basic specification is:

$$
\Delta \ln (\text { trade })_{i j t}=\alpha+\sum_{k=0}^{M} \beta_{k} \Delta \ln (\text { sea distance } i j, t-k)+\gamma_{t}+\epsilon_{i j t}
$$

where $\Delta \ln (\text { trade })_{i j t}$ is the change in log trade, $M$ is the number of lags, $\gamma_{t}$ is a set of year dummies, and $\epsilon_{i j t}$ is an error term. The change in sea distance between countries $i$ and $j$ in year $t-k, \Delta$ sea distance $_{i j, t-k}$, takes on a positive value in 1967 and a negative value in 1975 for countries pairs with shortest routes through the Suez Canal. A full set of country dummies can also be included, giving each country an individual trend. Doing so does not change the results in any significant way. Standard errors are clustered at the country level in all regressions.

The impulse response functions shown in the rest of the paper are constructed by summing the $\beta$ coefficients from estimating equation (10). The response in the contemporaneous period is $\beta_{0}$, for the second period $\beta_{0}+\beta_{1}$, and so on up to the total number of estimated lags.

$$
\text { response }_{t}=\sum_{k=0}^{t} \beta_{k}
$$

In each case the standard error of the sum is calculated. All impulse response function graphs include bands of two standard errors.

Figure 3 plots the time path of trade after a permanent shock to sea distance for both the full sample and the balanced panel. The magnitude is analogous to the elasticity estimates from Table 1. The response function suggests that it takes roughly three years for the shock to have its full impact with a long run elasticity of about -0.5, which is very similar to the sea distance results of column (3) in Table 2 and larger than the Table 1 regressions that include the transition years.

Figure 4 shows separate impulse response functions for the opening and closing of Suez. They are both drawn representing a positive shock to distance for com- 
Figure 3: The Response of bilateral Trade to Suez Distance Shocks
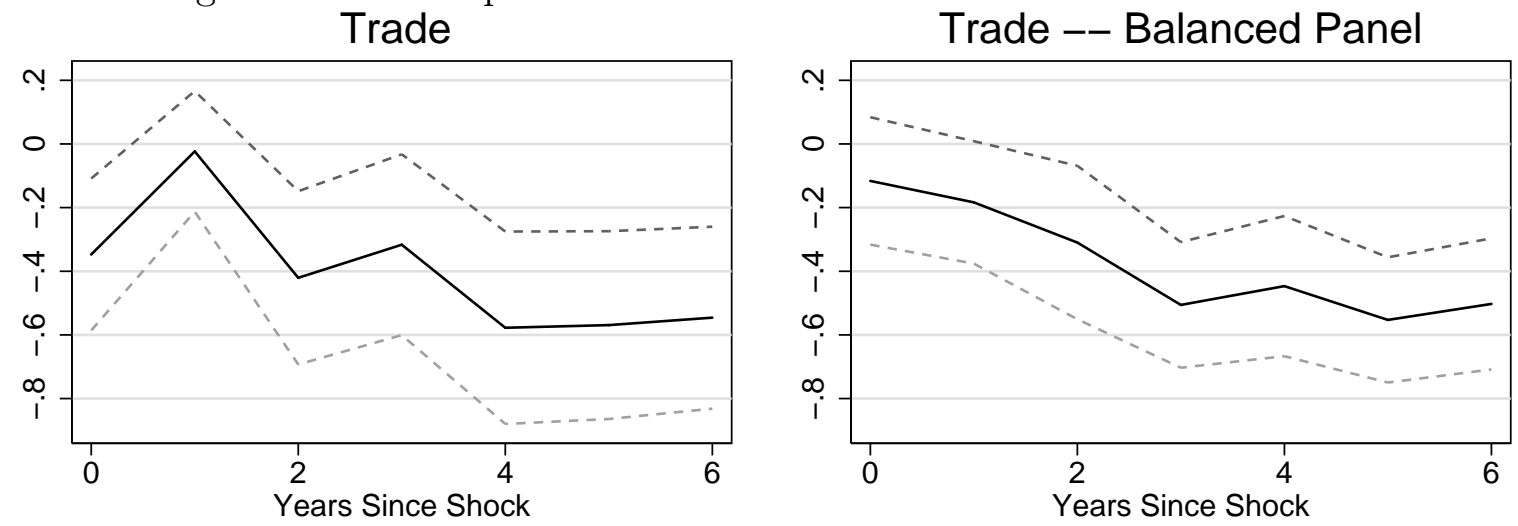

Dashed lines represent plus or minus two standard errors

Figure 4: The Response of Trade to Suez Distance Shocks
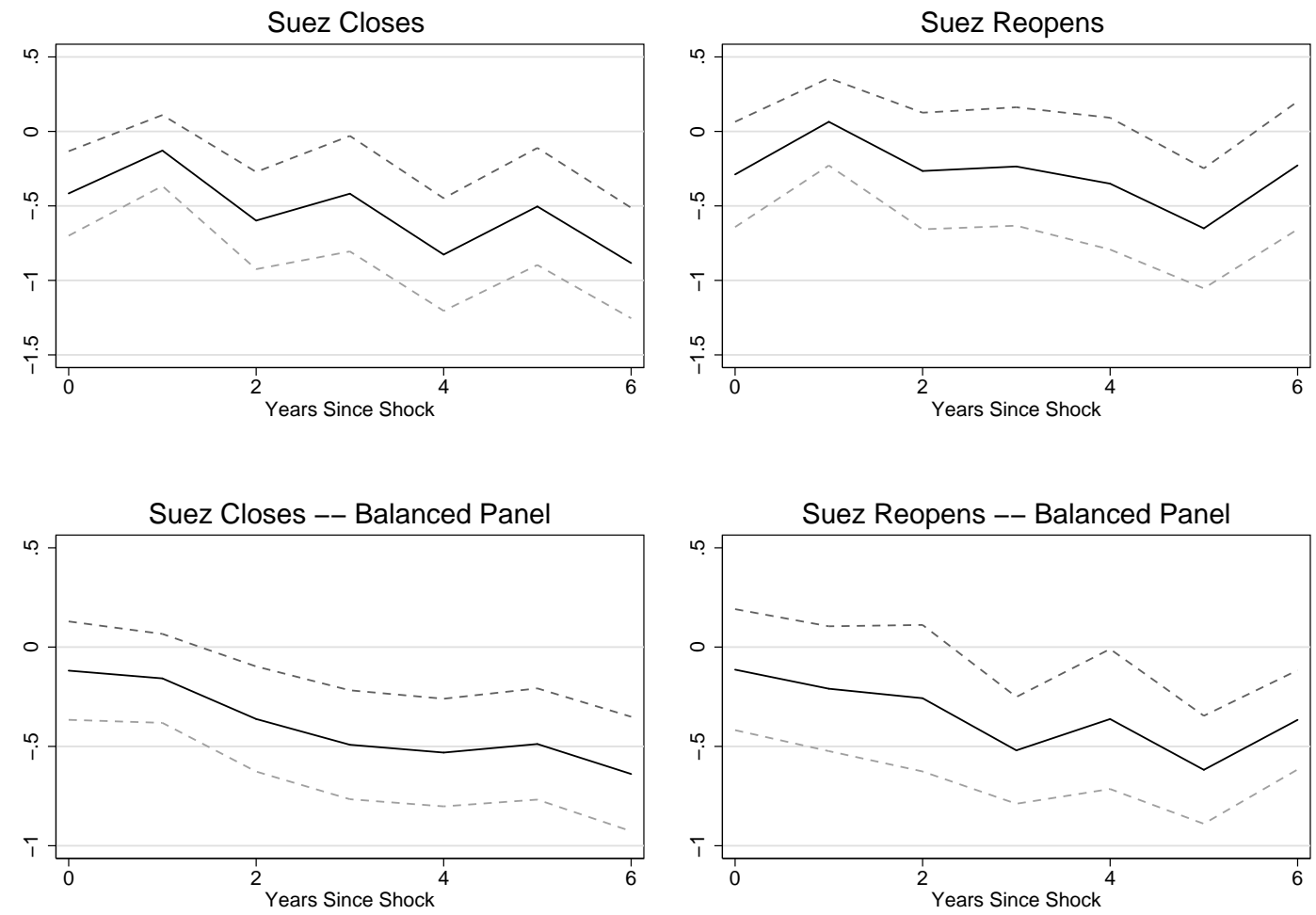

Dashed lines represent plus or minus two standard errors 
parative purposes. The opening and closing of the canal do not appear to generate substantially different time paths for trade. Both the up and down shocks generate an elasticity of roughly 0.5 when the full effect is in place though the impact of reopening is modestly smaller. This is similar to the earlier regressions. The largest differences between the opening and closing were found when the transition years were included. The long run impacts are much closer together and this can be seen in the impulse responses.

The closure and reopening of the Suez Canal appear to be useful shocks for thinking about changes in the costs of trade between nations. The long run elasticity of trade with respect to sea distance is roughly 0.5 , with the adjustment process taking about three years. The response to the reopening of the Suez Canal appears to be roughly the same in magnitude and time path as the closing of the canal. Since the closing was caused by the outbreak of war and the closing was caused by a peace agreement the similarity suggests that the true effect of transport costs on trade is being identified and not some indirect effect of the Six Day War.

\section{Trade and Income}

The previous section establishes that the closing and reopening of the Suez Canal affected bilateral trade between partners whose shortest sea route is through the Suez Canal. For any individual country these changes in distance were exogenous and generated entirely through differences in geography. Different countries were differentially effected depending on their geography and pre-existing trade patterns. These shocks to trade can therefore be used to identify the impact of changes in trade on income at the aggregate country level.

\subsection{Predicting Aggregate Trade}

The coefficients reported in Table 1 can be used to construct predicted values for bilateral trade for each pair of countries for each year. The predicted values are derived from equation (3) and are comprised of a time effect, a bilateral pair effect and the distance effect. These predicted trade volumes can be summed in order to arrive at a prediction for aggregate trade in each country for each year. I can also sum predictions based on the dynamic model represented by equation (10). These 
predictions have the advantage of plotting the change in trade over time rather than just portraying the shock as a single event.

These predictions can be made out of sample. As long as there is a single observation of bilateral trade between two countries, an estimate for the bilateral pair can be generated in every year since distance is always available. This has the advantage of keeping the set of bilateral pairs constant over time for the predicted trade, avoiding the problem of changes to aggregate trade driven by the appearance and disappearance of trade data for a particular pair.

Because the goal is to instrument the trade volumes with predicted trade in a regression of trade on per capita GDP, these out of sample predictions create some difficulties because there are observations where there is a predicted trade value, but not an actual trade value. This matters because the instruments and observations of trade volumes need to be matched for the IV regressions. To deal with this the missing values of trade are imputed using a full set of country pair and time dummies. These imputations are based entirely on information that is controlled for in the second stage and should not affect the results. They are only necessary to keep the scaling of the actual changes in trade consistent.

Following Frankel and Romer (1999), unlogged versions of these bilateral relationships are summed to obtain a prediction for total trade for each country. The actual trade figures are similarly summed to arrive at a value for total trade.

$$
\begin{aligned}
\text { predicted }_{\text {trade }} i t & =\sum_{i \neq j} e^{\hat{\gamma}_{t}+\hat{\gamma}_{i, j}+\ln \left(\text { sea distance }_{i j t}\right) * \hat{\beta}} \\
& =e^{\hat{\gamma}_{t}} \sum_{i \neq j} e^{\hat{\gamma}_{i j}} e^{\ln \left(\text { sea distance }_{i j t}\right) * \hat{\beta}}
\end{aligned}
$$

The country pair effects act as weights in an average of distances. Because the country level regressions will include country and time fixed effects, all the identification will be from the within country variation over time. None of the identifying time variation is generated from the bilateral or time effects.

The predictions based on the impulse response regressions are similar but require a transformation to generate useful predictions for the level of trade. Because the estimates are from differenced trade, two modifications are needed. First, there is no need to include the time controls since these will be controlled for in the second stage. Second, the summed change in trade needs to be scaled by average trade over the sample for each pair. The result is identical to equation (6) with the single sea 
distance term replaced with a summation of sea distance terms over lags.

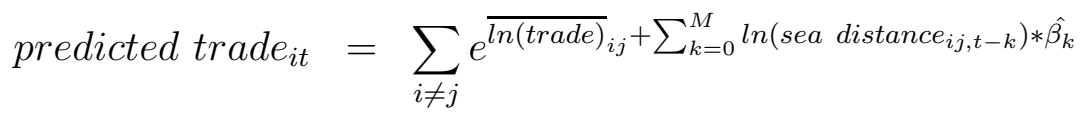

Additionally, I can construct a simpler and somewhat more transparent instrument. A weighted average of the distance change across all trading partners (using the average trade over the whole sample as the weight) will give me the average log distance change per unit of trade for each country. If I run a regression using this average log distance change over the change in log aggregate trade I should get a coefficient that is approximately equal to the $\beta$ from the bilateral level regression. For the panel regressions the instrument has value zero when the canal is open and the value of the shock when the canal is closed.

$$
\text { Suez_Shock }_{i}=\left(\overline{\operatorname{trade}_{i}}\right)^{-1} \sum_{i \neq j}\left(\ln \left(\text { seadist }_{\text {noSuez }}\right)-\ln \left(\text { seadist }_{\text {Suez }}\right)\right) * \overline{\operatorname{trade}_{i j}}
$$

Table 3 lists the countries in the income sample in order of the size of their shock to distance as calculated by equation 8 . The list is obviously very regional, with Pakistan and India experiencing about a 30 percent increase in average distance. Many East Asian countries experience a shock in the 10 percent range. Several East African countries also experience large shocks 14

Both the predicted trade from the trade regressions and the weighted average of the changes in distance derive all of their idiosyncratic variation from the opening and the closing of the Suez Canal. Since the Suez canal shocks are exogenous with respect to individual countries in the sample (the combatants and neighbors are excluded), this variation should provide a useful instrument for investigating the impact of trade on GDP.

\subsection{OLS Regression of Income on Trade}

Trade and GDP are highly correlated in the time series. Figure 5 shows a scatter plot of changes in trade versus changes in GDP per capita over the three major periods of this investigation. Both variables have been demeaned by country and

\footnotetext{
${ }^{14}$ Because this list is restricted to countries with income data for the second stage and excludes combatants and neighbors, several countries experiencing large shocks are not on this list. Jordan and Sudan experienced by far the largest distance shocks. Most other East African Countries also experienced large shocks.
} 
Table 3: Trade weighted Increase in Sea Distance from Suez Closure

\begin{tabular}{|c|c|c|c|c|c|}
\hline Country & Code & Increase & Country & Code & Increase \\
\hline Pakistan & $\overline{\mathrm{PAK}}$ & 31.4 & Ireland & IRL & 0.8 \\
\hline India & IND & 30.6 & Finland & FIN & 0.8 \\
\hline Kenya & $\mathrm{KEN}$ & 23.6 & Mauritania & MRT & 0.7 \\
\hline Sri Lanka & LKA & 20.4 & New Zealand & NZL & 0.4 \\
\hline Malaysia & MYS & 13.7 & Guinea-Bissau & GNB & 0.3 \\
\hline Madagascar & $\mathrm{MDG}$ & 13.4 & Iceland & ISL & 0.2 \\
\hline Mauritius & MUS & 11.2 & Sierra Leone & SLE & 0.2 \\
\hline Romania & $\mathrm{ROM}$ & 10.6 & Canada & $\mathrm{CAN}$ & 0.2 \\
\hline Vietnam & VNM & 10.6 & Barbados & BRB & 0.1 \\
\hline Singapore & SGP & 10.6 & Guyana & GUY & 0.1 \\
\hline Thailand & THA & 10.0 & Belize & BLZ & 0.1 \\
\hline China & $\mathrm{CHN}$ & 9.4 & Guinea & GIN & 0.1 \\
\hline Bulgaria & BGR & 7.2 & Bahamas, The & BHS & 0.1 \\
\hline Indonesia & IDN & 6.2 & Nicaragua & NIC & 0.1 \\
\hline Cyprus & CYP & 6.0 & Haiti & HTI & 0.0 \\
\hline Greece & GRC & 5.9 & Dominican Republic & DOM & 0.0 \\
\hline Philippines & PHL & 5.0 & Jamaica & JAM & 0.0 \\
\hline Mozambique & MOZ & 4.2 & Suriname & SUR & 0.0 \\
\hline Papua New Guinea & PNG & 4.0 & Mexico & MEX & 0.0 \\
\hline United Kingdom & GBR & 3.3 & Panama & PAN & 0.0 \\
\hline Malta & MLT & 3.3 & Peru & PER & 0.0 \\
\hline Korea, Rep. & KOR & 3.2 & Guatemala & GTM & 0.0 \\
\hline Italy & ITA & 2.9 & Costa Rica & CRI & 0.0 \\
\hline Australia & AUS & 2.5 & Honduras & HND & 0.0 \\
\hline Albania & ALB & 2.5 & South Africa & $\mathrm{ZAF}$ & 0.0 \\
\hline Japan & JPN & 2.4 & Ecuador & ECU & 0.0 \\
\hline Tunisia & TUN & 2.0 & Colombia & $\mathrm{COL}$ & 0.0 \\
\hline Morocco & MAR & 1.9 & Fiji & FJI & 0.0 \\
\hline Germany & $\mathrm{DEU}$ & 1.9 & Liberia & LBR & 0.0 \\
\hline Spain & ESP & 1.7 & El Salvador & SLV & 0.0 \\
\hline Netherlands & NLD & 1.5 & Argentina & $\mathrm{ARG}$ & 0.0 \\
\hline France & FRA & 1.5 & Benin & $\mathrm{BEN}$ & 0.0 \\
\hline Portugal & PRT & 1.3 & Brazil & BRA & 0.0 \\
\hline Gambia, The & GMB & 1.3 & Chile & CHL & 0.0 \\
\hline Sweden & SWE & 1.1 & Cote d'Ivoire & CIV & 0.0 \\
\hline Denmark & DNK & 1.0 & Cameroon & CMR & 0.0 \\
\hline Norway & NOR & 0.9 & Ghana & GHA & 0.0 \\
\hline United States & USA & 0.8 & Togo & TGO & 0.0 \\
\hline Bermuda & BMU & 0.8 & Uruguay & URY & 0.0 \\
\hline Senegal & SEN & 0.8 & Samoa & WSM & 0.0 \\
\hline
\end{tabular}


Figure 5: The Relationship between output and trade

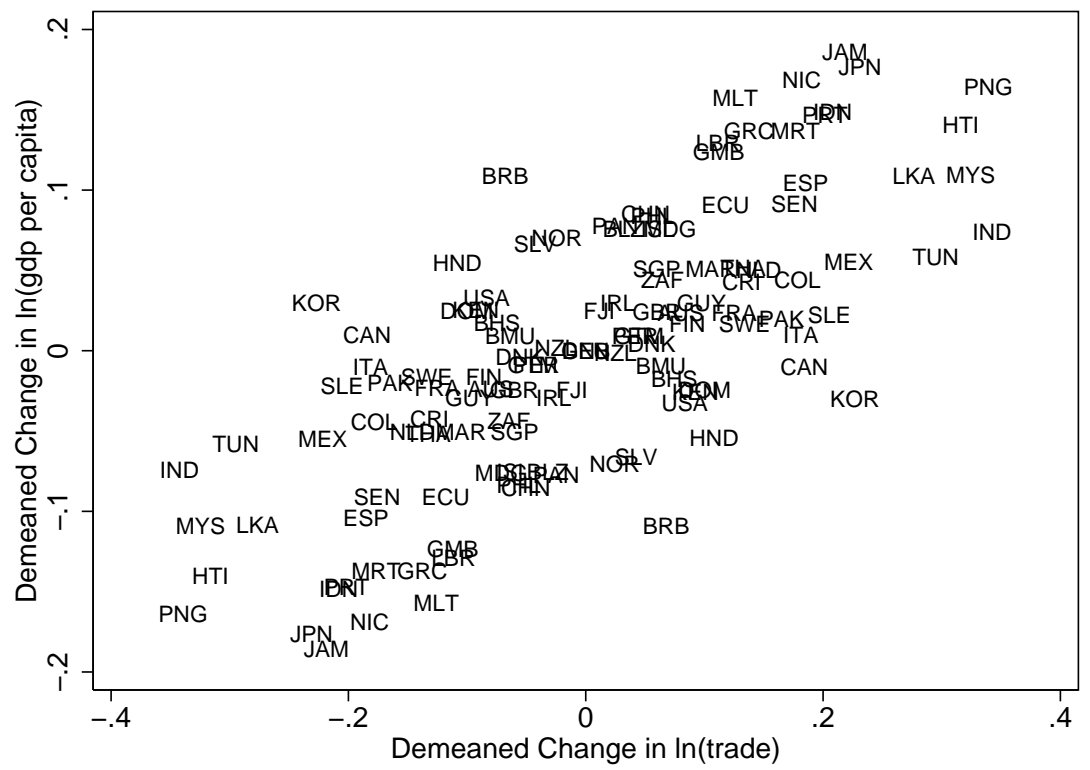

Source: IMF direction of trade database, World Development Indicators, author's calculations. Changes based on average for three periods, 1960-1966, 1970-1974, 1978-1984.

time so this is a visual representation of a regression in differences with the inclusion of both time dummies and individual country time trends. There are two points for each country on the graph; one for the change in average trade from the period before the closure (1960-1966) to during the closure (1970-1974) and a second for the change in average trade from the period during the closure (1970-1974) to after the Canal reopened (1978-1984).

Table 4 shows the results of regressing trade on GDP per capita in a regression with a set of country and time dummies. The estimating equation is

$$
\ln \left(y_{i t}\right)=\alpha+\gamma_{i}+\gamma_{t}+\beta \ln \left(\operatorname{trade}_{i t}\right)+\epsilon_{i t}
$$

where the dependent variable is real per capita income from the World Development Indicators and the independent variable is the volume of trade from the DOT database described earlier summed at the country level. Column 1 is the full sample and column 2 omits the transition years. There is obviously a strong and significant relationship between trade and income with an elasticity of about 0.30 .

The OLS regressions are, of course, unidentified since we do not know the direction of causality. In the next sections, instruments based on the shock to trade 
Table 4: Trade versus GDP per capita - OLS

\begin{tabular}{|c|c|c|}
\hline & $(1)$ & $(2)$ \\
\hline & \multicolumn{2}{|c|}{$\ln ($ GDP per capita $)$} \\
\hline \multirow[t]{2}{*}{$\ln ($ trade $)$} & $0.300^{* *}$ & $0.318^{* *}$ \\
\hline & $(0.053)$ & $(0.051)$ \\
\hline Countries & 80 & 80 \\
\hline Observations & 1,771 & 1,351 \\
\hline R-squared & 0.994 & 0.994 \\
\hline Transition Years Included & Yes & No \\
\hline
\end{tabular}

Years 1967-1969 and 1975-1977 are the transition periods.

Regressions include country and year dummies.

Standard errors clustered by country

from the closure of the Suez canal will be used to establish a causal link between trade and output.

\subsection{IV regressions}

Table 5 presents the results of IV regression of income on trade. There are several variations presented. Three different instruments are used. The first instrument is the simple aggregate shock from equation (8). This instrument has the value of simplicity and transparency. The second instrument is derived from predicted values of trade from equation (6) using estimates from column (2) of Table $1{ }^{15}$ The third instrument is derived from the impulse response function of Figure 3 summed using equation (7). Unlike the other two instruments, which have two changes occurring in 1967 and 1975, this instrument captures the complete dynamic response to the canal closure and reopening. The other variation in Table 5 is between regressions that omit the transition years and those that include them. For the static instruments, the inclusion of the transition years should bias the coefficient estimates downward by averaging in years with partial adjustment. It should make no difference for the dynamic instrument since it already incorporates the transition.

The first stage results suggest that the instruments are powerful. In each case they are significant at the one percent level with F-stats above the standard threshold of 10 suggested by Staiger and Stock (1997). For the static instruments, the first

\footnotetext{
${ }^{15}$ For the IV regressions, it doesn't matter which of the first four columns is used since it just rescales the size of the shock. It does affect the magnitude of the reduced form regressions, but not their significance levels.
} 
Table 5: Output and Trade
(1)
(2)
(3)
(4)
(5)
(6)

IV RESULTS

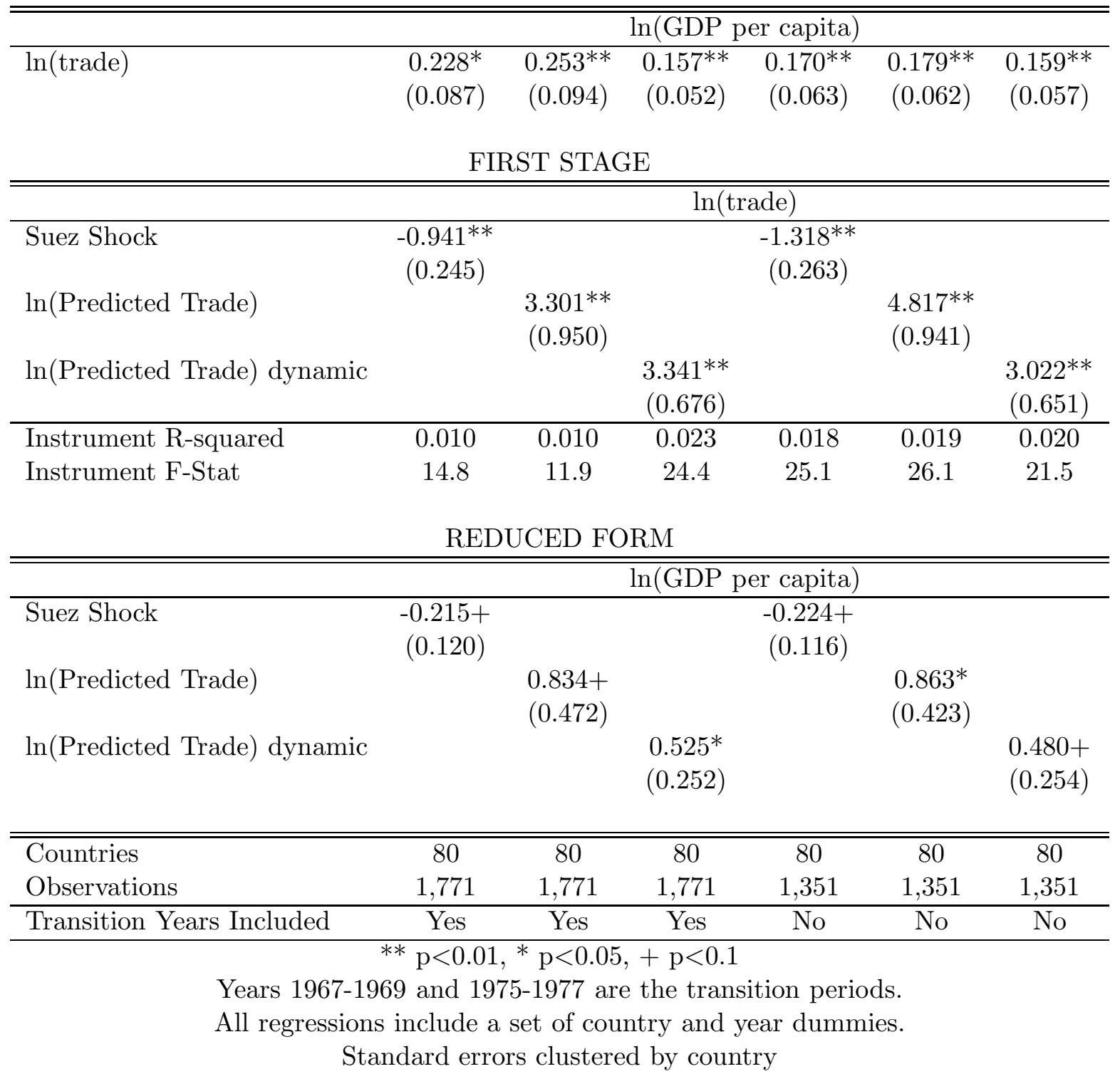


Figure 6: Log change in trade versus Suez Distance Shock

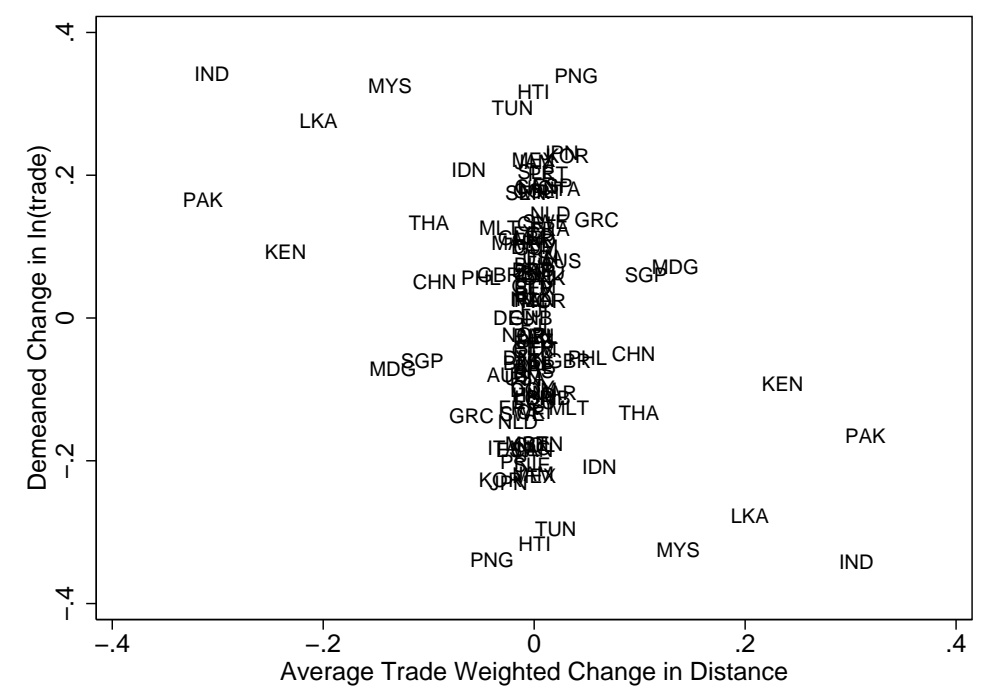

Source: IMF direction of trade database, author's calculations.

Trade change based on average for three periods, 1960-1966, 1970-1974, 1978-1984.

Figure 7: Log change in GDP per capita versus Suez Distance Shock

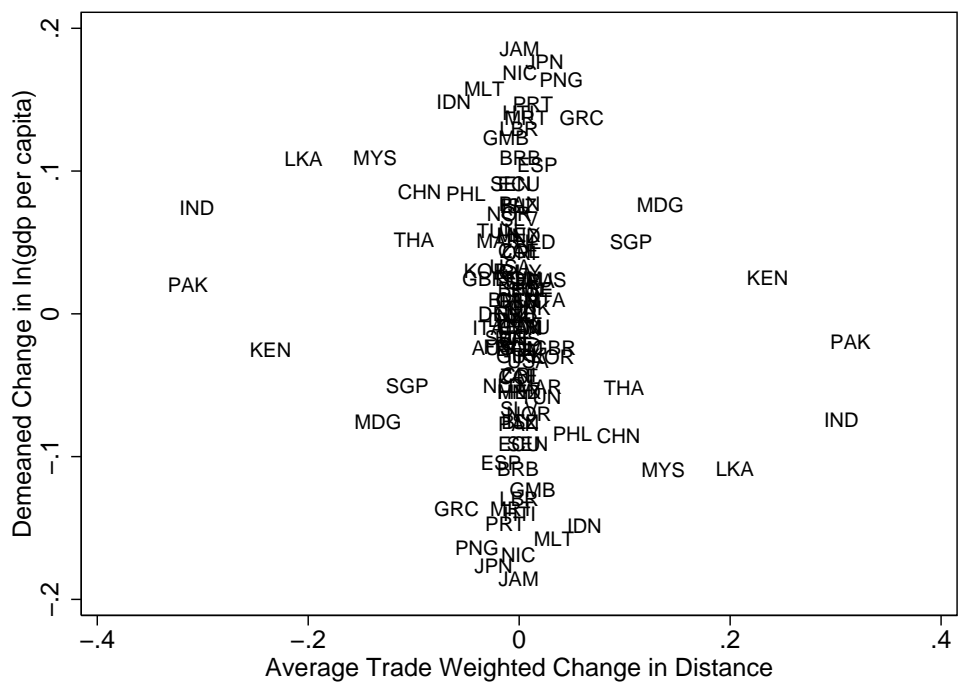

Source: World Development Indicators, author's calculations.

GDP change based on average for three periods, 1960-1966, 1970-1974, 1978-1984. 
stage is stronger when the transition years are omitted. For the dynamic instrument the opposite is true. Unsurprisingly, using the dynamic instrument with the full set of years generates the strongest first stage. Figure 6 shows a scatter plot of actual trade changes versus the average distance change caused by the closure and reopening of Suez. Countries experiencing a larger shock see larger swings in trade during the closure of the canal.

Figure 7 shows a scatter plot of the log change in GDP per capita versus the average distance change caused by the closure and reopening of Suez. Table 5 shows the same reduced form relationship in regressions on the full panel of data. The coefficients are all significant (though some are only marginally so) and the precision of the estimates improves in logical ways across estimates. For the two static instruments, the precision improves when the transition years are omitted. For the dynamic instrument the opposite is true. The strongest instrument (dynamic predictions on the full set of years) generates the most precise reduced form.

Table 5 shows the results of IV regression where actual trade is instrumented with the predicted values of trade derived earlier and the average distance change caused by the closing and opening of Suez. The elasticity of trade with respect to income is between 0.15 and 0.25 and the estimates are significantly away from zero in all cases.

These magnitudes are less than half the values found in Feyrer (2009) which relies on the rise in the relative importance of air travel for identification 16 This comparison is interesting because the use of air travel allows for things other than trade such as movements of people to play a role. Because the identification is coming from the change in sea distance, these estimates are much more clearly identifying the effect of trade in goods and not integration or globalization in general. The comparison of the two provides an estimate of how much of the former paper's results are driven by pure trade in goods and how much is other features of globalization. These results suggest about half from trade and half from other aspects of globalization.

\subsection{Impulse Response Functions at the Country Level}

The earlier impulse response functions were drawn for data at the country pair level. The same exercise is possible for the aggregated country level data. The advantage

\footnotetext{
${ }^{16}$ The elasticities are much smaller than Frankel and Romer (1999), which finds a coefficient of almost 2 on trade shares versus income.
} 
Figure 8: Aggregate Response of Trade to Suez Distance Shocks

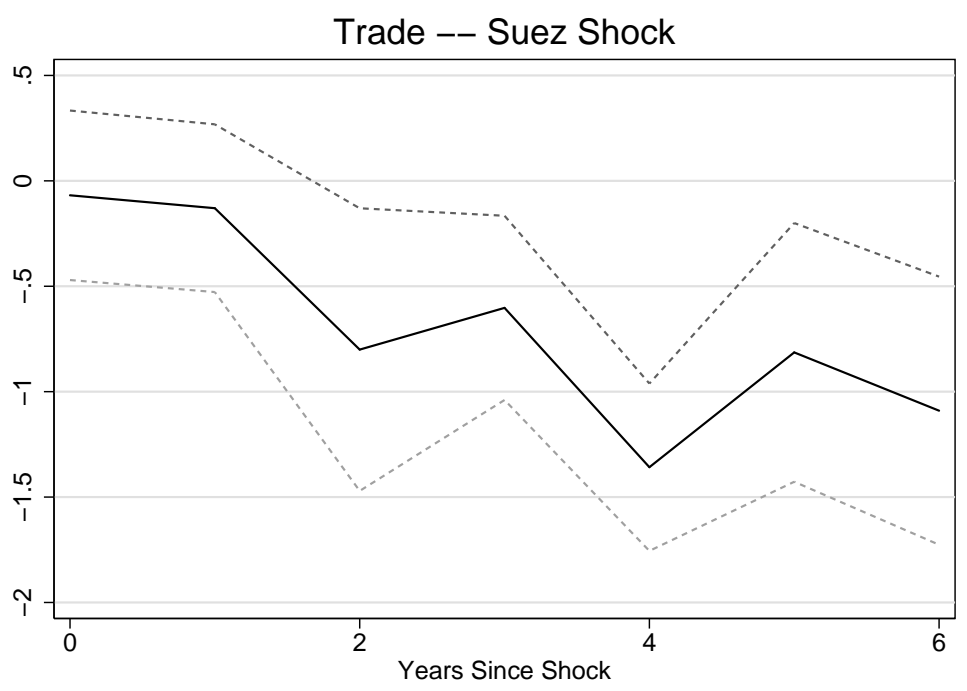

Dashed lines represent plus or minus two standard errors

of this approach is that I can draw the time path of the shocks on output as well as trade. The estimating equation is

$$
\Delta \ln \left(y_{i t}\right)=\alpha+\sum_{k=0}^{M} \beta_{k} \Delta \ln \left(X_{i, t-k}\right)+\gamma_{t}+\epsilon_{i t}
$$

where $\Delta \ln (y)_{i t}$ is the change in log per capita income (or trade), $M$ is the number of lags, $\gamma_{t}$ is a set of year dummies, and $\epsilon_{i j t}$ is an error term. The key right hand side variable, $\ln \left(X_{i t}\right)$, will take on the value of trade or one of the instruments depending on the specification. The impulse response function is generated by summing the $\beta^{\prime} s$ as described in equation (5). All response functions are drawn with a surrounding band of two standard errors.

Figure 8 shows the impulse response function of country level trade to the shock of closing Suez, where the shock is measured as the trade weighted average of the increase in distance caused by the closing of Suez described in equation (8). Figure 9 shows the impulse response functions of trade when the shock is separated into the opening and closing.

These response functions are roughly the same shape as the pair level response functions in Figures 3 and 4 . This is unsurprising since they are an aggregation of the bilateral data. The first stage results from Table 5 show that the closure of the 
Figure 9: Aggregate Response of Trade to Suez Distance Shocks

1967 Suez Close

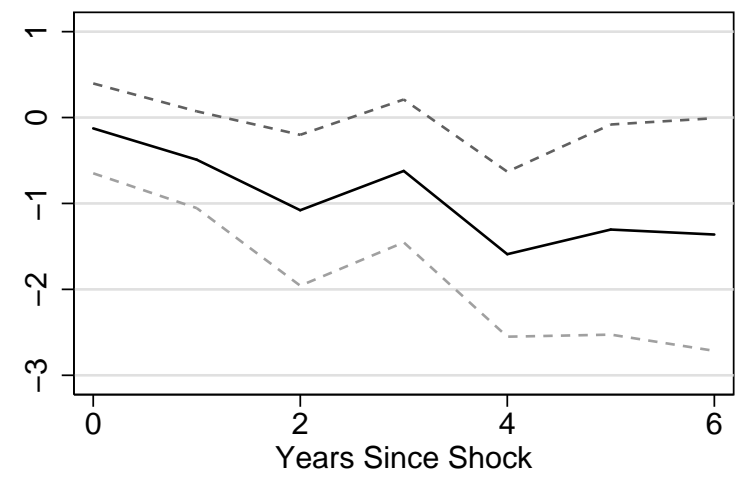

1975 Suez Reopen

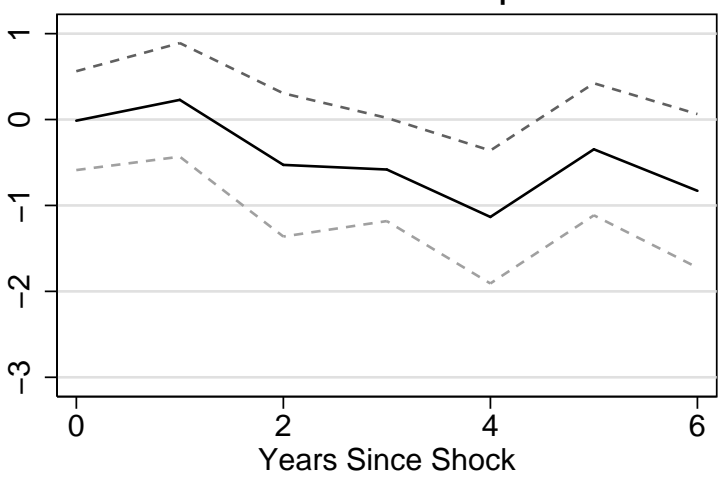

Dashed lines represent plus or minus two standard errors

canal had a significant impact on aggregate trade. Adjustment after the shock takes three to four years.

Identifying the effect on the shock on GDP is somewhat more difficult as there are two levels of adjustment. First, the shock of closing the canal moves trade with some lag. Trade may then move GDP with its own lag structure.

$$
\mathrm{SUEZ} \mathrm{SHOCK} \Rightarrow l a g \Rightarrow \mathrm{TRADE} \Rightarrow l a g \Rightarrow \mathrm{GDP}
$$

Estimating reduced form impulse response functions of the static instruments on GDP will generate the combination of these lag structures. Using the dynamic predictions for trade will isolate the second lag structure. Using IV regressions to estimate the impulse response function can also be used to isolate this second lag structure. The basic idea is to estimate equation (10) using the trade predictions and lags as instruments.

Figure 10 shows nine impulse response functions. Each column represents a different instrument. The first is the simple shock as calculated in equation (8). The second is the static predictions from the gravity estimations. The third is the dynamic predictions from the disaggregated trade impulse response functions. The three rows are first stage, reduced form and IV responses to the instruments.

The first row is the impulse response of trade on each of the instruments. This is essentially the first stage of the IV regressions. The shock has a significant impact on trade with adjustment occurring over three to four years. In all cases, the response is significantly away from zero at the one percent level by the second year. The 
Figure 10: The Response of GDP to Trade Shocks
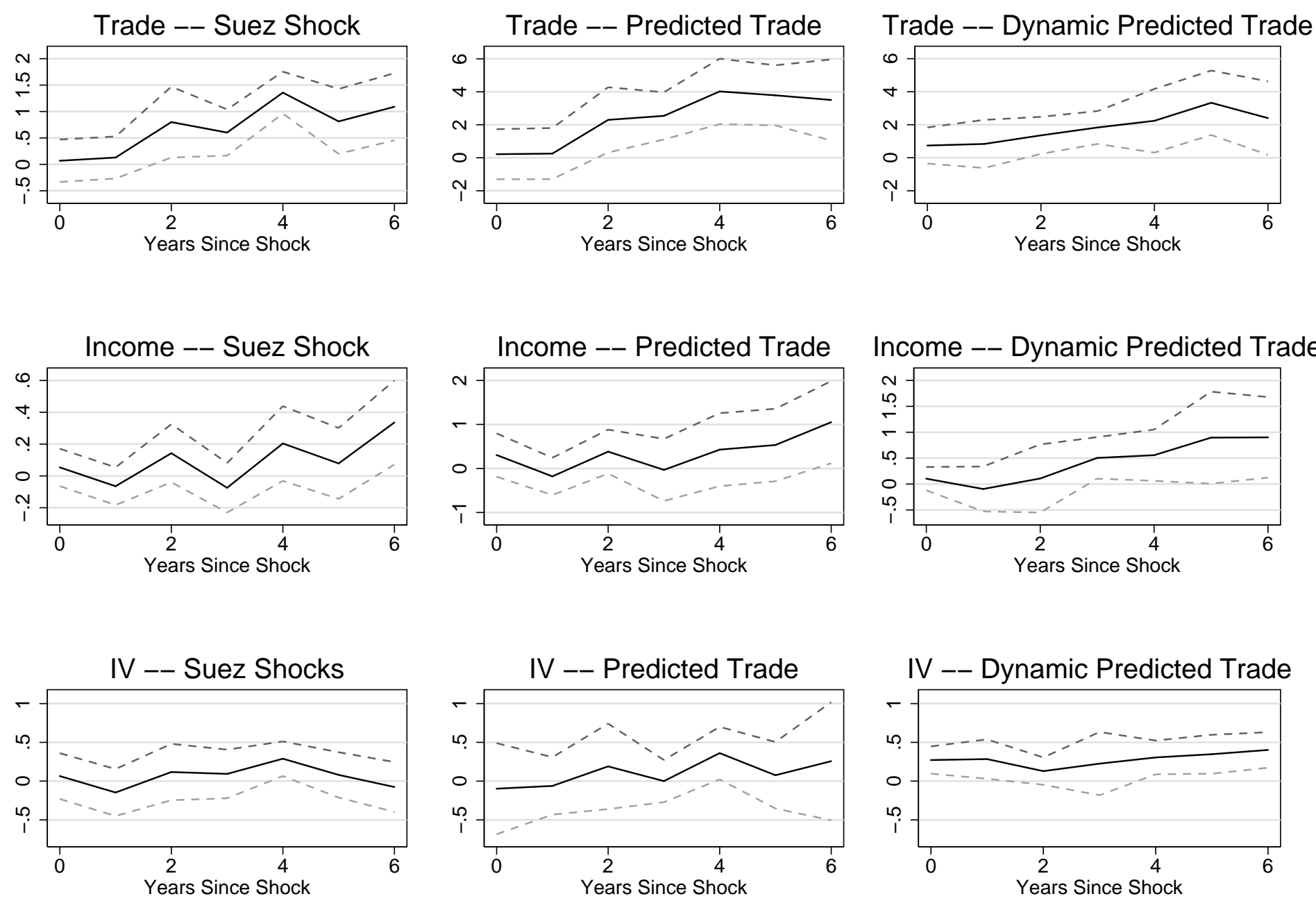

Dashed lines represent plus or minus two standard errors 
Figure 11: The OLS Response of GDP to Trade Shocks Income (OLS)

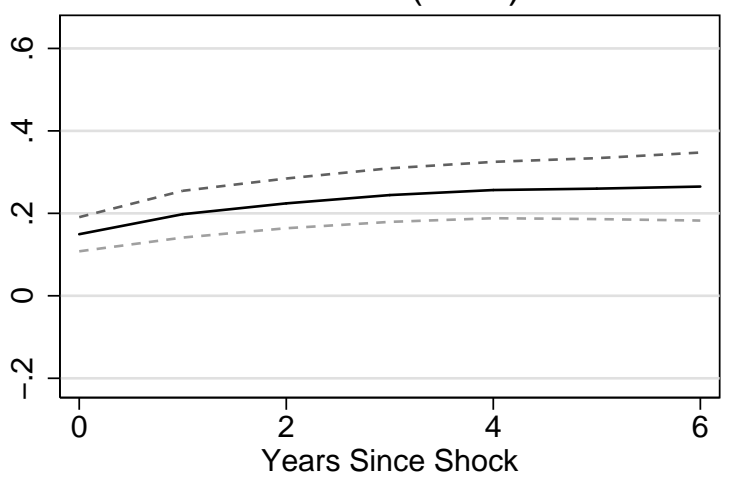

IV -- Dynamic Predicted Trade

Dashed lines represent plus or minus two standard errors

dynamic instrument has a flatter curve, consistent with the instrument already incorporating the dynamic response to the shock.

The second row is the reduced form effect of the instruments on income per capita. For the first two columns the static instruments will capture the combined lag structure of the Suez shock to trade and trade to GDP. For the dynamic instrument the response function represents just the lag structure from trade to GDP. Consistent with this, the impulse response functions for the static instruments rise later and are significantly away from zero only in the sixth year. The response continues to rise in year six. The response from the dynamic instrument captures only the lag from trade to GDP and rises faster and is significantly away from zero after the third year. Income appears to take four to five years to adjust to a trade shock.

All three IV impulse response functions isolate the lag structure from trade to GDP. These results also have the advantage of magnitudes that are interpretable as elasticities of income on trade. For all three instruments the response rises over time with a peak somewhere near the fourth year. Consistent with the regression results the peak of the response function is between 0.2 and 0.4 for all three cases. The response is significantly away from zero in the fourth year in all three cases and in all the later years for the dynamic instrument. Figure 11 compares the IV impulse response from the dynamic instrument to the OLS impulse response from using actual trade (and lags) as the right hand side variable. The shape and magnitude are similar.

The use of shocks to trade generated by the closing and reopening of the Suez Canal provide clean identification on the impact of trade on income. The results 
suggest that increases in trade volumes generated by decreases in trade costs generate higher income per capita. The elasticity of income with respect to trade appears to be about one quarter, with an adjustment period of three to four years. Lags in the effect on GDP of decreasing trade costs are closer to five years adding in the response of trade volumes to trade costs.

\section{Conclusions}

This paper uses the shock provided by the temporary closure of the Suez Canal as a natural experiment. The movements in trade costs generated by closing Suez can be usefully thought of as an exogenous shock effecting most countries in the world. This shock is useful for identifying the impact of trade costs on trade and furthermore the effect of trade on income. To summarize, the Suez Canal had a significant and robust affect on bilateral trade patterns. Aggregating these changes to trade suggests that trade has a significant affect on output.

The nature of the canal shock makes it unique. First, the shock was sudden and short term. We have precise dates when the shocks took place. Second, the shocks are very precisely targeted at trade by sea. Generally when we consider instruments for trade, they can potentially act through channels that go beyond trade. Since the variation in this paper is being provided by the Suez closure, any channels other than trade need to involve bilateral relationships between countries that involve travel by sea. It is hard to imagine anything other than trade in goods than fits this description.

The ability to get clean identification on the effect of trade in goods on output is potentially useful when considering the effect of policies designed to reduce trade costs between nations. This paper suggests that while activities that are related to trade such as foreign direct investment and multinational participation may be important, simple increases in the raw volume of trade increase income. This may be useful in evaluating policies intended to increase trade such as tariff reductions. 


\section{References}

Anderson, James E. and Eric van Wincoop, "Gravity with Gravitas: A Solution to the Border Puzzle," American Economic Review, March 2003, 93 (1), 170-192.

Baldwin, Richard and Daria Taglioni, "Gravity for Dummies and Dummirs for Gravity Equations," Working Paper 12516, National Bureau of Economic Research September 2006.

Blum, B.S. and A. Goldfarb, "Does the internet defy the law of gravity?," Journal of International Economics, 2006, 70 (2), 384-405.

Coulibalya, Souleymane and Lionel Fontagne, "South - South Trade: Geography Matters," Journal of African Economies, 2005, 15 (2), 313-341.

Disdier, A.C. and K. Head, "The Puzzling Persistence of the Distance Effect on Bilateral Trade," The Review of Economics and Statistics, 2008, 90 (1), 37-48.

Dollar, David, "Outward-Oriented Developing Economies Really Do Grow More Rapidly: Evidence from 95 LDCs, 1976-1985," Economic Development and Cultural Change, 1992, 40 (3), 523.

Edwards, Sebastian, "Openness, Productivity and Growth: What Do We Really Know?," The Economic Journal, 1998, 108 (447), 383-398.

Feyrer, James, "Trade and Income - Exploiting Time Series in Geography," Working Paper 14910, National Bureau of Economic Research April 2009.

Frankel, Jeffrey and David Romer, "Does Trade Cause Growth?," American Economic Review, June 1999, 89 (3), 379-99.

Glick, R. and A.M. Taylor, "Collateral Damage: Trade Disruption and the Economic Impact of War," Review of Economics and Statistics, 2008. forthcoming.

Grossman, Gene M., "Comment," in Jeffrey A. Frankel, ed., The Regionalization of the World Economy, University Of Chicago Press, 1998.

Head, K. and T. Mayer, "Illusory Border Effects: Distance Mismeasurement Inflates Estimates of Home Bias in Trade," 2002.

Heston, Alan, Robert Summers, and Bettina Aten, "Penn World Table Version 6.2," Technical Report, Center for International Comparisons of Production, Income and Prices at the University of Pennsylvania September 2006.

Irwin, D.A. and M. Terviö, "Does trade raise income? Evidence from the twentieth century," Journal of International Economics, 2002, 58 (1), 1-18. 
Johnson, Simon, William Larson, Chris Papageorgiou, and Arvind Subramanian, "Is Newer Better? Penn World Table Revisions and Their Impact on Growth Estimates," Working Paper 15455, National Bureau of Economic Research October 2009.

Mayer, Thierry and Soledad Zignago, "Notes on CEPII's distance measures," 2006.

Meehl, G.A., "Observed World Ocean Seasonal Surface Currents on a 5-degree Grid," NCAR Technical Note, 1980.

Rodriguez, Francisco and Dani Rodrik, "Trade Policy and Economic Growth: A Skeptic's Guide to the Cross-National Evidence," NBER Macroeconomics Annual, 2000, 15, 261-325.

Rodrik, D., A. Subramanian, and F. Trebbi, "Institutions Rule: The Primacy of Institutions Over Geography and Integration in Economic Development," Journal of Economic Growth, 2004, 9 (2), 131-165.

Sachs, Jeffrey D. and Andrew Warner, "Economic Reform and the Process of Global Integration," Brookings Papers on Economic Activity, 1995, 1, 1-118.

Staiger, D. and J.H. Stock, "Instrumental variables regression with weak instruments," Econometrica: Journal of the Econometric Society, 1997, pp. 557-586.

Summers, R. and A. Heston, "The Penn World Tables Mark 5.5 (updated supplement to The Penn World Tables (Mark 5): An Expanded Set of International Comparisons 1950-1988)," Quarterly Journal Of Economics, May 1991, 106, 327-368. 